\title{
Dioxolanylium Ions Derived from Carbohydrates. VIII. Nucleophilic trans-Opening with Sulfur- and Nitrogen-containing Neighbouring Groups
}

\author{
STEFFEN JACOBSEN and OLE MOLS
}

Department of Organic Chemistry, The Technical University of Denmark, DK-2800 Lyngby, Denmark

The use of the rearrangement of dioxolanylium ions containing a trans vicinal neighbouring group to introduce a thio or amino-deoxy function into carbohydrates has been investigated. The neighbouring groups studied were thionobenzoate, xanthate, carbamate, thiocarbamate, benzimidate and carbonate.

Two preceding papers in this series have dealt with the reaction between dioxolanylium ions derived from carbohydrates and a variety of nucleophilic reagents. ${ }^{1,2}$ Among the reagents which could be incorporated in the carbohydrate molecules as a result of trans opening of the dioxolanylium ion was, e.g., halide, trifluoroacetate and tosylate, while the reaction was unsuccessful with simple nitrogen nucleophiles as, e.g., azide and phthalimide ion, a rather unsatisfactory state of affairs, since this reaction would have led to the important aminosugars. The failure of the reaction in these cases was not due to lack of reactivity of the chosen nitrogen-containing nucleophiles, but rather to the ambident nature of the dioxolanylium ion. While trans opening to the thermodynamically more stable product $^{3}$ is a result of attack on the dioxolanylium ion at the carbon centers $a$ or $b$ (see Scheme 1), the nitrogen nucleophiles all attack at carbon c yielding<smiles>[X]C1([R])OCCO1</smiles><smiles>[R][C@@]1(C)O[C@H]([2H])[C@H](O)O1</smiles><smiles>[Y]C1CC1</smiles><smiles>[X]CCOC([R])=O</smiles>

Scheme 1. orthoacid derivatives. These orthoacid derivatives are sufficiently stable to render the rearrangement to $\beta$-substituted esters too slow to compete with the general destruction of the carbohydrate part of the molecule under the reaction conditions employed; more stable substrates, however, are known to undergo trans opening with nitrogen nucleophiles. ${ }^{4}$ In order to avoid the orthoester formation a new approach has been introduced to the nucleophilic opening of dioxolanylium ions, namely inclusion of the nucleophile as a trans vicinal neighbouring group (see Scheme 2). The purpose of this is twofold;

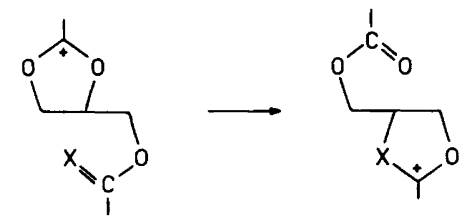

Scheme 2.

firstly, anchoring of the nucleophile to the trans substituent makes the intramolecular attack at C-2 in the dioxolanylium ion highly improbable, compared with the alternative attack at C-3 and C-4; secondly, previous results ${ }^{5}$ pertaining to ester neighbouring groups, indicate that regiospecific attack on the vicinal carbon atom is strongly preferred, while intermolecular trans-opening often yields both of the two possible products.

The substrates for the present investigation consisted of a number of derivatives of 1,6-anhydro$3,4-O$-benzylidene- $\beta$-D-galactopyranose (1), the benzylidene group serving as the precurser for the 
Table 1. ${ }^{1} \mathrm{H}$ NMR spectra of benzoxonium ions in acetonitrile- $d_{3}$ solution.

\begin{tabular}{|c|c|c|c|c|c|c|c|c|c|c|c|c|c|c|c|}
\hline \multirow{2}{*}{$\begin{array}{l}\text { Com- } \\
\text { pound }\end{array}$} & \multicolumn{8}{|c|}{ Chemical shifts ( $\delta$-values) } & \multicolumn{7}{|c|}{ Coupling constants $(\mathrm{Hz})$} \\
\hline & $\mathrm{H} 1$ & $\mathrm{H} 2$ & $\mathrm{H} 3$ & $\mathrm{H} 4$ & $\mathrm{H} 5$ & $\mathrm{H} 6$ & $\mathrm{H} 6^{\prime}$ & & $J_{12}$ & $J_{23}$ & $J_{34}$ & $J_{45}$ & $J_{56}$ & $J_{56^{\prime}}$ & $J_{66^{\prime}}$ \\
\hline $6 c$ & 5.77 & 5.18 & 5.98 & 6.40 & 5.08 & & $3.8-$ & & $<1$ & $<1$ & 9.8 & 6.5 & & & \\
\hline $7 d$ & 6.32 & 5.74 & 5.06 & 5.49 & 4.99 & 4.46 & 3.98 & & 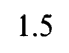 & 8.0 & 7.8 & .1 & .0 & 5.3 & .7 \\
\hline $7 e$ & 6.17 & 5.58 & 4.96 & 5.44 & 4.98 & 4.41 & 3.95 & $\begin{array}{l}2.97 \\
\mathrm{NH}_{2}\end{array}$ & 1.5 & 7.2 & 7.8 & 5.4 & 1.4 & 5.4 & 9.1 \\
\hline $7 f$ & 5.86 & 5.27 & 5.74 & 5.53 & 4.96 & 4.27 & 3.81 & $\begin{array}{l}8.76 \\
\mathrm{NH}_{2}\end{array}$ & 1.0 & 8.4 & 4.0 & 6.0 & 1.2 & 5.3 & 8.8 \\
\hline $7 g$ & 5.96 & 5.18 & 4.61 & 5.48 & 4.90 & 4.33 & 3.85 & $\begin{array}{l}9.44 \\
\mathrm{NCH}_{3}\end{array}$ & 1.5 & 6.5 & 8.2 & 4.8 & 1.0 & 5.2 & 8.7 \\
\hline $7 h$ & 5.97 & 5.41 & 5.10 & 5.84 & 5.06 & 4.32 & 3.84 & 3.61 & $\simeq 1$ & 10.3 & 5.1 & 6.2 & 1.0 & 5.5 & 8.9 \\
\hline
\end{tabular}

dioxolanylium ion and the hydroxy group at C-2 serving as the attachment site for the trans neighbouring group. From previous investigations it is known that when the neighbouring group is benzoyl the galacto-benzoxonium ion $6 a$ rearranges to give $96-97 \%$ of the gulo-benzoxonium ion $7 a$, i.e., the neighbouring group effect from a group attached to C-2 is possible and favoured in this case. $^{6}$

The first nucleophile studied was divalent sulfur with thionobenzoate and xanthate serving as the corresponding neighbouring groups. When 1,6anhydro-3,4- $O$-benzylidene-2- $O$-thiobenzoyl- $\beta$-Dgalactopyranose $(5 d)$ was treated with trityl tetrafluoroborate in acetonitrile, only one product, the thioxanylium ion $7 d$, resulted as seen from the ${ }^{1} \mathrm{H}$ and ${ }^{13} \mathrm{C}$ NMR-spectra. The proton chemical shifts (Table 1) closely resembled those of $7 a^{6}$ with exception of H-3, which showed a large upfield shift, while the coupling constants suggested a somewhat less flattened ${ }^{1} \mathrm{C}_{4}$ conformation for the pyranose ring when compared to $7 a$, as would be expected from the longer C-S bonds. Similarly the ${ }^{13} \mathrm{C}$ chemical shift (Table 2) for C-3 showed a large upfield shift ( $37 \mathrm{ppm}$ ), while $\mathrm{C}-2$ and $\mathrm{C}-4$ showed smaller downfield shifts ( 9 and $4 \mathrm{ppm}$, respectively) compared to those of $7 a$. The carbonium ion carbon absorbed at $214 \mathrm{ppm}$, well outside the range previously found $(175-185 \mathrm{ppm})$ for carbohydrate benzoxonium ions, but in agreement with the value expected for a thioxanylium ion. ${ }^{7}$ Hydrolysis of the thioxanylium ion $7 d$ gave 1,6-anhydro-2,4-di- $O$ benzoyl-3-thio- $\beta$-D-gulopyranose (10), which was purified as the acetate in order to avoid oxidation to the disulfide. When 1,6-anhydro-3,4-Obenzylidene-2- $O$-(methylthio)thiocarbonyl- $\beta$-D-galactopyranose $(5 e)$ was oxidized with trityl tetrafluoroborate to give the galacto-benzoxonium ion $6 e$, this also rearranged to the gulo-ion $7 e$ as judged from its ${ }^{1} \mathrm{H}$ and ${ }^{13} \mathrm{C}$ NMR spectra. Hydrolysis of the ion $7 e$ gave 1,6-anhydro-4- $O$-benzoyl-3-thio-2$0,3-S$-thiocarbonato- $\beta$-D-gulopyranose (4) presumably via an orthoacid derivative. Treatment of the ion $7 e$ with bromide ion caused dealkylation of the

Table $2 .{ }^{13} \mathrm{C}$ chemical shifts ( $\delta$-values) of benzoxonium ions in acetonitrile- $d_{3}$ solution.

\begin{tabular}{llllllllll}
\hline Compound & $\mathrm{C} 1$ & $\mathrm{C} 2$ & $\mathrm{C} 3$ & $\mathrm{C} 4$ & $\mathrm{C} 5$ & $\mathrm{C} 6$ & $\mathrm{C}+$ & $\mathrm{CO}$ & $\mathrm{CH}_{3}$ \\
\hline $6 c$ & 98.2 & 71.4 & 84.5 & 78.4 & 68.6 & 63.1 & 182.0 & & \\
$7 d$ & 96.0 & 92.7 & 50.0 & 72.0 & 71.1 & 62.6 & 213.9 & 164.7 & \\
$7 e$ & 95.8 & 93.7 & 51.0 & 72.1 & 71.4 & 63.6 & 222.6 & 165.3 & 18.4 \\
$7 f$ & 95.8 & 80.6 & 82.9 & 68.9 & 70.2 & 63.4 & $165.0^{a}$ & $164.5^{a}$ & \\
$7 g$ & 95.9 & 87.3 & 48.0 & 72.7 & 71.6 & 63.4 & 184.9 & 165.2 & \\
$7 h$ & 96.4 & 80.9 & 64.6 & 69.2 & 70.0 & 63.4 & 171.9 & 164.8 & 35.9 \\
\hline
\end{tabular}

${ }^{a}$ Assignment may be reversed. 
<smiles>OC1C2OC3C(O)C1O[C@@H](c1ccccc1)C3O2</smiles>

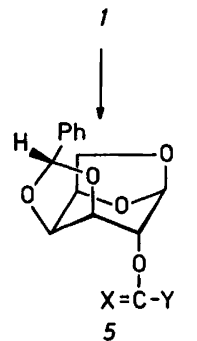

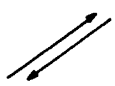

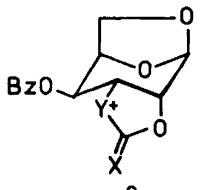<smiles>NC(=O)C1OC2CC(C(=O)O)C1OC2O</smiles><smiles>O=C1OC2CC3OC2C(O1)C3OC(=O)c1ccccc1</smiles>

3

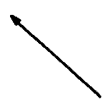<smiles></smiles>
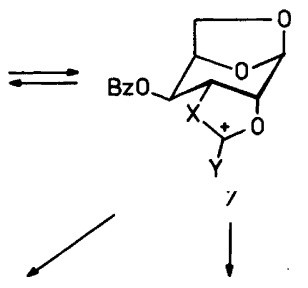

\%
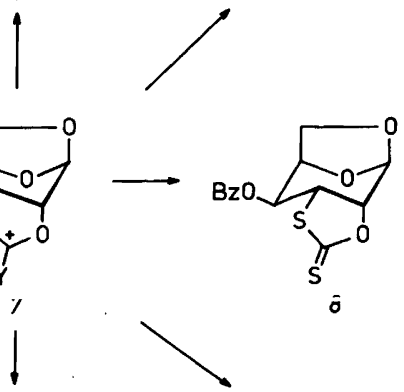<smiles>O=C1OC2C3OC(CC3OC(=O)c3ccccc3)C2S1</smiles>

${ }_{4}$

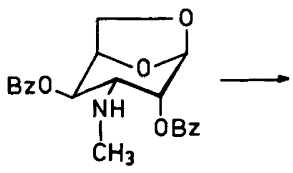

11

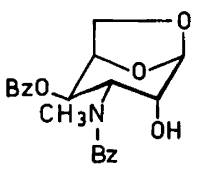

12

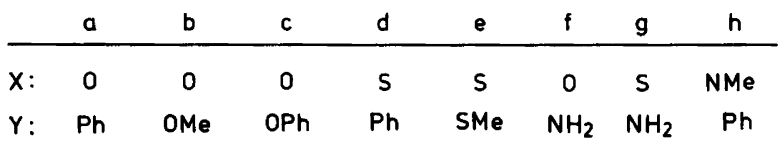

Scheme 3.

exocyclic methylthio-group leading to the cyclic xanthate 8 (1,6-anhydro-4-O-benzoyl-3-thio-2-O,3$S$-dithiocarbonato- $\beta$-D-gulopyranose).

In order to introduce a nitrogen functionality into the carbohydrate part of the molecule the effect of a carbamate, a thiocarbamate and an iminoester as neighbouring group was investigated. Due to the ambident nature of the amide grouping attack on the benzoxonium ion could conceivably occur with the oxygen as well as the nitrogen atom; one would expect an attack from the oxygen atom, to give $7 f$, as a result of kinetic control, while equilibrating conditions should lead to a product $9 f$, formally from attack by the nitrogen atom. When 1,6anhydro-3,4- $O$-benzylidene-2- $O$-carbamoyl- $\beta$-D-galactopyranose $(5 f)$ was treated with trityl tetrafluoroborate no galacto-benzoxonium ion $6 f$ could be observed in the ${ }^{1} \mathrm{H}$ NMR-spectrum, but the product was the 2-amino-1,3-dioxolanylium ion $7 f$, which showed no tendency to rearrange to the 2-oxo-1,3-oxazolidinium salt $9 f$ when left at $40^{\circ} \mathrm{C}$ for one month. When treated with water $7 f$ gave two products, 1,6-anhydro-4-O-benzoyl-2- $O$-carbamoyl- $\beta$-D-gulopyranose $(2,53 \%)$ and 1,6 anhydro-4- $O$-benzoyl-2,3- $O$-carbonato- $\beta$-D-gulopyranose $(3,8 \%)$, presumably both formed via the same intermediate orthoacid derivative. The neighbouring group effect of the thiocarbamate group closely resembled that of the carbamate. Treatment of 1,6-anhydro-3,4-O-benzylidene-2- $O$-thiocarbamoyl- $\beta$-D-galactopyranose $(5 g)$ with trityl fluoroborate gave the 2-amino-1,3-oxathiolanylium ion $7 \mathrm{~g}$, which did not show any tendency to rearrange to the 2-thioxo-1,3-oxazolidinium salt $9 g$ after 1 month at $40^{\circ} \mathrm{C}$. Hydrolysis of $7 g$ proceeded to give the cyclic thiocarbonate 4 described above. In contrast to the bidentate neighbouring groups discussed so far the iminoester grouping offers only a nitrogen atom as the attacking site. When 1,6anhydro-3,4- $O$-benzylidene-2-O- $(N$-methyl)benzimidoyl- $\beta$-D-galalctopyranose $(5 h)$ was treated with trityl tetrafluoroborate, hydride abstraction took place to give the galactobenzoxonium ion $6 h$, which rearranged completely to the $N$-methyl-oxazolinium 
ion $7 h$, as seen from a ${ }^{1} \mathrm{H}$ and ${ }^{13} \mathrm{C}$ NMR spectrum. This ion was stable in strong mineral acid $(2-4 \mathrm{M}$ $\mathrm{HBF}_{4}$ ), but on dilution to $0.1 \mathrm{M} \mathrm{HBF}_{4}$ hydrolysis took place to give 1,6-anhydro-2,4-di-O-benzoyl-3deoxy-3-( $N$-methyl)amino- $\beta$-D-gulopyranose $\quad(11)$ isolated as its hydrochloride. Hydrolysis under neutral conditions gave 1,6-anhydro-4- $O$-benzoyl-3deoxy - 3- $(N$-methyl)benzamido- $\beta$-D-gulopyranose (12), which rearranged to 11 when treated with trifluoroacetic acid in chloroform.

The cyclic carbonate 3 isolated from the rearrangement of the carbamate $6 f$ was prepared in a different manner. When 1,6-anhydro-3,4-O-benzylidene-2- $O$-methoxycarbonyl- $\beta$-D-galactopyranose $(5 b)$ was treated with trityl tetrafluoroborate the cyclic carbonate 3 could be isolated directly in $82 \%$ yield. When the reaction was followed by ${ }^{1} \mathrm{H}$ and ${ }^{13} \mathrm{C}$ NMR spectroscopy in deuterioacetonitrile none of the dioxolanylium ions $6 b$ and $7 b$ could be detected, but the cyclic carbonate 3 appeared directly, accompanied by $N$-methyldeuterioacetonitrilium fluoroborate. ${ }^{8,9}$ Addition of water to the reaction mixture gave unchanged 3 and $N$-methyldeuterioacetamide. This observation suggested that the reaction followed the normal path to give the galacto-benzoxonium ion $6 b$ by hydride abstraction, followed by rearrangement to the alkoxy-dioxolanylium ion $7 b$, which, being a strong alkylating agent, ${ }^{10,11}$ was rapidly dealkylated by the solvent. Indeed, when the reaction was carried out in deuterionitromethane the transitory existence of a galacto-benzoxonium ion was observed in the ${ }^{13} \mathrm{C}$ NMR-spectrum in the initial stages of the reaction, but also in this case complete dealkylation took place to give solely 3 after $24 \mathrm{~h}$. In order to allow a more leisurely observation of the galacto-gulo ion formation and equilibration the attention was turned to the corresponding phenoxycarbonyl compounds where dealkylation would be unlikely. When 1,6-anhydro-3,4-O - benzylidene-2- $O$-phenoxycarbonyl- $\beta$-D-galactopyranose $(5 c)$ was treated with trityl tetrafluoroborate overnight, the major product was the galacto-benzoxonium ion $6 c$ as seen from a ${ }^{13} \mathrm{C}$ NMR spectrum. A small amount of the cyclic carbonate 3 was also observed, its amount slowly increasing until after $\mathrm{ca} .1$ month this was the major product, in this case presumably not as a result of dealkylation, but rather as a result of hydrolysis due to water formed by the slow destruction of part of the carbohydrate compounds present. Assignment of the structure $6 c$ to the benzoxonium ion formed was made on basis of a comparison with the previously described gulo- and galactobenzoxonium ions. ${ }^{6}$ The strong preference ( $>90 \%$ ) for the galacto ion $6 c$ observed here, leads to the conclusion, that a 2-alkoxy- or aryloxy-dioxolanylium ion is much less stable than a 2-aryldioxolanylium ion. The literature contains contradictory information with regard to the stability of di- and tri-alkoxy substituted carbonium ions. ${ }^{12-15}$

The benzylidene compounds used as precursors for the dioxolanylium ions were prepared in the following manner. The carbonates $5 b$ and $5 c$ were made by acylation of 1,6-anhydro-3,4-O-benzylidene- $\beta$-D-galactopyranose (1) with methoxyand phenoxycarbonyl chloride in pyridine. The thionobenzoate $5 d$ was prepared by treatment of the alkohol 1 with sodium hydride in tetrahydrofuran catalyzed by imidazole to facilitate the formation of the sodium alkoxide of 1 , followed by treatment with (thiobenzoylthio)acetic acid. ${ }^{16}$ The sodium salt of 1 was also used to prepare the $x$ anthate ester $5 e$ by treatment with carbon disulfide followed by alkylation with methyl iodide. The carbamate $5 f$ and thiocarbamate $5 g$ were prepared by ammonolysis of the esters $5 c$ and $5 e$, respectively, and the iminoester $5 h$ by acylation with $N$-methylbenzimidoyl chloride. Conventional acylation of benzylidene galactosan (1) in pyridine gave only starting material, whereas the alkoxide of 1 , formed as described above, reacted smoothly to give the iminoester $5 h$.

\section{EXPERIMENTAL}

Thin-layer chromatography (TLC) was performed on silica gel $\mathrm{PF}_{254}$ (Merck), for preparative work 1 $\mathrm{mm}$ layers were used on $20 \times 40 \mathrm{~cm}$ plates. Compounds were visualized by UV light. Melting points are uncorrected. Optical rotations were measured in chloroform solution on a Perkin-Elmer 141 instrument. ${ }^{1} \mathrm{H}$ NMR spectra were measured on Bruker HXE 90 and HX 270 instruments and ${ }^{13} \mathrm{C}$ NMR spectra on a Bruker WH 90 instrument. All spectra were measured in deuteriochloroform unless otherwise specified. IR spectra were measured in $\mathrm{KBr}$ on a Perkin-Elmer 421 spectrometer.

1,6-Anhydro-3,4-O-(S)-benzylidene-2-O-thiobenzoyl- $\beta$-D-galactopyranose ( $5 \mathrm{~d})$. To a solution of (thiobenzoylthio)acetic acid $(848 \mathrm{mg})$ in THF (50 $\mathrm{ml}$ ) was added $600 \mathrm{mg}$ of a $55 \%$ suspension of sodium hydride in mineral oil followed by $400 \mathrm{mg}$ of imidazole. After reflux for $5 \mathrm{~min} 500 \mathrm{mg}$ of $1,6-$ anhydro-3,4- $O-(R)$-benzylidene- $\beta$-D-galactoside (1) (the exo-H isomer erroneously assigned the $(S)$ - 
configuration in Ref. 6) was added and the reflux continued for $10 \mathrm{~min}$. Excess sodium hydride was destroyed by careful addition of a small amount of water and the reaction mixture was poured into water and extracted with ether. The organic phase was washed with water, dried $\left(\mathrm{MgSO}_{4}\right)$ and evaporated to dryness. Crystallization from benzenemethanol gave $298 \mathrm{mg}(40 \%)$ of $5 d$ m.p. 127$129^{\circ} \mathrm{C}$. One recrystallization gave an analytical sample, m.p. $129-130^{\circ} \mathrm{C},[\alpha]_{\mathrm{D}}{ }^{25}+126^{\circ}$ (c 0.9$)$. Anal. $\mathrm{C}_{20} \mathrm{H}_{18} \mathrm{O}_{5} \mathrm{~S}: \mathrm{C}, \mathrm{H}, \mathrm{S} .{ }^{1} \mathrm{H}$ NMR: $\delta 5.69(\mathrm{H} 1)$, $6.03(\mathrm{H} 2), 4.40(\mathrm{H} 3), 4.7$ (H4, H5), 4.23 (H6), 3.60 $\left(\mathrm{H}^{\prime}\right) ; J_{12}, J_{23}, J_{56}<1 \mathrm{~Hz}, J_{66}=7.8 .{ }^{13} \mathrm{C} \mathrm{NMR}$ : $\delta 98.7$ (C1), 76.6 (C2), 75.5 (C3), 69.6 (C4), 72.7 (C5), 63.6 (C6), 103.1 ( $\mathrm{ArCH}) 209.0(\mathrm{C}=\mathrm{S})$.

1,6-Anhydro-2,4-di-O-benzoyl-3-thio- $\beta$-D-gulopyranose (10). $5 d(370 \mathrm{mg})$ was treated with trityl fluoroborate $(404 \mathrm{mg})$ in acetonitrile $(10 \mathrm{ml})$ at $20^{\circ} \mathrm{C}$ for $16 \mathrm{~h}$ and hydrolyzed with aqueous $\mathrm{NaHCO}_{3}$. Extraction with chloroform followed by drying $\left(\mathrm{MgSO}_{4}\right)$ and preparative TLC (etherpentane $1: 1)$ gave $298 \mathrm{mg}(77 \%)$ of 10 as a sirup, homogeneous according to NMR, but difficult to purify to analytical purity. ${ }^{1} \mathrm{H}$ NMR: $\delta 5.68(\mathrm{H} 1)$, $5.25(\mathrm{H} 2), 3.57$ (H3), 5.42 (H4), 4.80 (H5), 4.23 (H6), $3.80\left(\mathrm{H}^{\prime}\right), 1.80(\mathrm{SH}) ; J_{12}=2.0 \mathrm{~Hz}, J_{23}=4.5, J_{34}=$ $10.8, J_{45}=3.9, J_{56}=1.0, J_{56^{\prime}}=4.9, J_{66^{\prime}}=8.1, J_{3 \mathrm{SH}}=$ 10.1 .

In another experiment from $386 \mathrm{mg}$ of $5 d$ the crude product was acetylated with acetic anhydride in pyridine to give $386 \mathrm{mg}$ of 1,6-anhydro-3-Sacetyl-2,4-di- $O$-benzoyl-3-thio- $\beta$-D-gulopyranose (13) after preparative TLC (ethyl acetate-pentane $1: 1)$. Rechromatography in chloroform gave 13 as a sirup, $[\alpha]_{\mathrm{D}}{ }^{25}+208^{\circ}(c 1.0)$, anal. $\mathrm{C}_{22} \mathrm{H}_{20} \mathrm{O}_{7} \mathrm{~S}: \mathrm{C}, \mathrm{H}$, S. ${ }^{1} \mathrm{H}$ NMR: $\delta 5.61(\mathrm{H} 1), 5.20(\mathrm{H} 2), 4.52(\mathrm{H} 3), 5.42$ (H4), 4.78 (H5), 4.38 (H6), 3.82 (H6'), 2.22 (Ac); $J_{12}=2.1 \mathrm{~Hz}, J_{23}=4.6, J_{34}=10.8, J_{45}=3.8, J_{56} \simeq$ $0.5, J_{56^{\prime}}=4.8, J_{66^{\prime}}=8.0$.

1,6-Anhydro-3,4-O-(S)-benzylidene-2-O-(methylthio) thiocarbonyl- $\beta$-D-galactopyranose $(5 \mathrm{e})$. To a solution of benzylidene galactosan $(1,3.0 \mathrm{~g})$ and imidazole $(30 \mathrm{mg})$ in THF $(50 \mathrm{ml})$ was added $1.2 \mathrm{~g}$ of sodium hydride in mineral oil $(55 \%)$ and the suspension was stirred at $20^{\circ} \mathrm{C}$ for $20 \mathrm{~min}$. Carbon disulfide $(6 \mathrm{ml})$ was added and the stirring continued for $1 \mathrm{~h}$, followed by addition of methyl iodide (1.5 $\mathrm{ml}$ ) and further $1 \mathrm{~h}$ stirring at $20^{\circ} \mathrm{C}$. After addition of acetic acid to destroy excess sodium hydride the reaction mixture was poured into water and extracted with chloroform, which upon drying and concentration yielded crystalline $5 e$. Recrystallization from ethyl acetate - pentane gave $3.33 \mathrm{~g}(82 \%)$ of $5 e$, m.p. $113.5-114^{\circ} \mathrm{C},[\alpha]_{\mathrm{D}}{ }^{25}+94^{\circ}$ (c 2.2). Anal. $\mathrm{C}_{15} \mathrm{H}_{16} \mathrm{O}_{5} \mathrm{~S}_{2}: \mathrm{C}, \mathrm{H}, \mathrm{S} .{ }^{1} \mathrm{H}$ NMR: $\delta 5.62(\mathrm{H} 1), 5.87$ (H2), $4.33(\mathrm{H} 3), 4.6(\mathrm{H} 4, \mathrm{H} 5), 4.18(\mathrm{H} 6), 3.57\left(\mathrm{H6}^{\prime}\right)$, $5.87(\mathrm{ArCH}), 2.63\left(\mathrm{CH}_{3} \mathrm{~S}\right) ; J_{12}, J_{23}, J_{56}<1 \mathrm{~Hz}$, $J_{66}=7.8 .{ }^{13} \mathrm{C}$ NMR: $\delta 98.6$ (C1), 78.1 (C2), 74.5
(C3), 69.4 (C4), 72.3 (C5), 63.7 (C6), 103.2 (ArCH), $214.9(\mathrm{C}=\mathrm{S})$.

1,6-Anhydro-4-O-benzoyl-3-thio-2-O,3-S-thiocarbonato- $\beta$-D-gulopyranose (4). 5 e $(504 \mathrm{mg})$ was treated with trityl fluoroborate $(715 \mathrm{mg})$ in acetonitrile $(10 \mathrm{ml})$ at $20^{\circ} \mathrm{C}$ for $16 \mathrm{~h}$. Hydrolysis with aqueous $\mathrm{NaHCO}_{3}$ for $5 \mathrm{~min}$, extraction with chloroform and crystallization from ether gave $324 \mathrm{mg}$ $(71 \%)$ of 4 , m.p. $143-146^{\circ} \mathrm{C}$. Recrystallization from ethyl acetate - pentane gave m.p. $146-147^{\circ} \mathrm{C}$, $[\alpha]_{\mathrm{D}}{ }^{25}+133^{\circ}\left(\right.$ c. 1.1). Anal. $\mathrm{C}_{14} \mathrm{H}_{12} \mathrm{O}_{6} \mathrm{~S}: \mathrm{C}, \mathrm{H}, \mathrm{S}$. IR: $1710-1740 \mathrm{~cm}^{-1}{ }^{1} \mathrm{H}$ NMR: $\delta 5.85$ (H1), 4.58 (H2), $4.06(\mathrm{H} 3), 5.51(\mathrm{H} 4), 4.91(\mathrm{H} 5), 4.24(\mathrm{H} 6), 3.86$ $\left(\mathrm{H}^{\prime}\right) ; J_{12}=1.6 \mathrm{~Hz}, J_{23}=6.4, J_{34}=9.0, J_{45}=4.5$, $J_{56} \simeq 0.5, J_{56^{\prime}}=5.3, J_{66^{\prime}}=8.4 .{ }^{13} \mathrm{C}$ NMR: $\delta 97.2$ (C1), 78.6 (C2), 45.7 (C3), 74.2 (C4), 71.8 (C5), 63.6 (C6), 164.8 (Bz), 170.0 (SCOO). Preparative TLC (ethyl acetate-pentane 1:2) of the mother liquor gave further $97 \mathrm{mg} \mathrm{(21 \% )} \mathrm{of} 4$.

1,6-Anhydro-4-O-benzoyl-2-O,3-S-dithiocarbonato3-thio- $\beta$-D-gulopyranose (8). To the thioxanylium ion $7 e$ from $502 \mathrm{mg}$ of $5 e$ and $698 \mathrm{mg}$ of trityl fluoroborate was added $0.5 \mathrm{~g}$ of tetraethylammonium bromide and the solution was left for $16 \mathrm{~h}$ at $20^{\circ} \mathrm{C}$. Work-up as described above and crystallization from ether gave $357 \mathrm{mg}(\simeq 75 \%)$ of a $1: 5$ mixture of 4 and 8 . Several recrystallataions from ethyl acetate-pentane gave pure 8 , m.p. 147$148^{\circ} \mathrm{C}[\alpha]_{\mathrm{D}}{ }^{25}+234^{\circ}$ (c 1.7). Anal. $\mathrm{C}_{14} \mathrm{H}_{12} \mathrm{O}_{5} \mathrm{~S}_{2}$ : C, H, S. IR: $1725 \mathrm{~cm}^{-1}(\mathrm{Bz}) .{ }^{1} \mathrm{H}$ NMR: $\delta 5.84(\mathrm{H} 1)$, $4.90(\mathrm{H} 2), 4.08$ (H3), 5.46 (H4), 4.87 (H5), 4.17 (H6), $3.83\left(\mathrm{H}^{\prime}\right) ; J_{12}=1.7 \mathrm{~Hz}, J_{23}=6.2, J_{34}=8.7, J_{45}=$ $4.5, J_{56}=0.8, J_{56^{\prime}}=5.8, J_{66^{\prime}}=8.2, J_{46^{\prime}}=1.2 .{ }^{13} \mathrm{C}$ NMR: $\delta 97.0$ (C1), 87.6 (C2), 49.0 (C3), 73.7 (C4), 71.9 (C5), 63.6 (C6), 166.0 (Bz), 210.0 (SCSO).

1,6-Anhydro-3,4-O-(S)-benzylidene-2-O-carbamoyl- $\beta$-D-galactopyranose ( $5 \mathrm{f})$. To a solution of $5 c(1.00 \mathrm{~g})$ in dichloromethane $(15 \mathrm{ml})$ was added $15 \mathrm{ml}$ of a saturated solution of ammonia in methanol, the solution was left at $20^{\circ} \mathrm{C}$ for $6 \mathrm{~h}$ and evaporated to dryness. Solution in chloroform and extraction with aqueous sodium carbonate and water gave, after drying and concentration, crystalline $5 f$. Recrystallization from chloroform - pentane gave $636 \mathrm{mg}(80 \%)$ of $5 f$, m.p. $182-184^{\circ} \mathrm{C}$, $[\alpha]_{\mathrm{D}}{ }^{25}+42^{\circ}$ (c 1.2). Anal. $\mathrm{C}_{14} \mathrm{H}_{15} \mathrm{NO}_{6}: \mathrm{C}, \mathrm{H}, \mathrm{N}$. IR: $1735,1710 \mathrm{~cm}^{-1} .{ }^{1} \mathrm{H}$ NMR: $\delta 5.44(\mathrm{H} 1), 4.98$ (H2), 4.30 (H3), 4.5 (H4, H5), 4.10 (H6), 3.51 (H6'), $5.82(\mathrm{ArCH}), 4.98\left(\mathrm{NH}_{2}\right) ; J_{12}, J_{23}, J_{56}<1 \mathrm{~Hz}$, $J_{66}=7.8$.

1,6-Anhydro-4-O-benzoyl-2-O-carbamoyl- $\beta$-Dgulopyranose (2). Treatment of $5 f(597 \mathrm{mg})$ with trityl fluoroborate $(860 \mathrm{mg})$ in acetonitrile $(10 \mathrm{ml})$ at $20^{\circ} \mathrm{C}$ for $16 \mathrm{~h}$ gave after stirring with aqueous $\mathrm{NaHCO}_{3}$ for 15 min and preparative TLC (ethyl acetate-pentane $3: 1) 46 \mathrm{mg}(8 \%)$ of the cyclic carbonate 3 (see below), m.p. $214-216^{\circ} \mathrm{C}$, followed by $329 \mathrm{mg}(53 \%)$ of 2 . Crystallization from ethyl 
acetate-pentane gave m.p. $202-204{ }^{\circ} \mathrm{C},[\alpha]_{\mathrm{D}}{ }^{25}$ $+89^{\circ}$ (c 1.0). Anal. $\mathrm{C}_{14} \mathrm{H}_{15} \mathrm{NO}_{7}: \mathrm{C}, \mathrm{H}, \mathrm{N} .{ }^{1} \mathrm{H}$ NMR (acetonitrile- $\left.\mathrm{d}_{3}\right): \delta 5.41(\mathrm{H} 1), 4.81(\mathrm{H} 2), 4.08(\mathrm{H} 3)$, 5.08 (H4), 4.60 (H5), 4.09 (H6), 3.59 (H6'), 3.32 (OH), $5.24\left(\mathrm{NH}_{2}\right) ; J_{12}=2.5 \mathrm{~Hz}, J_{23}=5.0, J_{34}=9.4, J_{45}=$ $4.0, J_{56}=0.5, J_{56^{\prime}}=4.9, J_{66^{\prime}}=8.1, J_{46}=1.0$.

1,6-Anhydro-3,4-O-(S)-benzylidene-2-O-thiocarbamoyl- $\beta$-D-galactopyranose $(5 \mathrm{~g})$. To $5 e(1.00 \mathrm{~g})$ in $25 \mathrm{ml}$ of THF was added $5 \mathrm{ml}$ of liquid ammonia and the solution was allowed to come to room temperature. After $1 \mathrm{~h}$ a further $5 \mathrm{ml}$ of liquid ammonia was added and the solution was again allowed to come to room temperature $(1 \mathrm{~h})$. Evaporation to dryness and crystallization from ethyl acetatepentane gave $0.60 \mathrm{~g}(66 \%)$ of $5 \mathrm{~g}$, m.p. $207-211^{\circ} \mathrm{C}$. Two recrystallizations gave an analytical sample, m.p. $\quad 214-215^{\circ} \mathrm{C}, \quad[\alpha]_{D}^{25}+66^{\circ} \quad(c \quad 0.5)$. Anal. $\mathrm{C}_{14} \mathrm{H}_{15} \mathrm{NO}_{5} \mathrm{~S}: \mathrm{C}, \mathrm{H}, \mathrm{N}, \mathrm{S} .{ }^{1} \mathrm{H}$ NMR: $\delta 5.55(\mathrm{H} 1)$, 5.61 (H2), 4.25 (H3), 4.5 (H4, H5), 4.13 (H6), 3.53 $\left(\mathrm{H6}^{\prime}\right), 5.85(\mathrm{ArCH}), 6.0-6.5\left(\mathrm{NH}_{2}\right) ; J_{12}, J_{23}$, $J_{56}<1 \mathrm{~Hz}, J_{66^{\prime}}=7.8$.

Reaction of the ion $7 \mathrm{f}$ with water. Treatment of $5 f$ $(392 \mathrm{mg})$ with trityl fluoroborate in acetonitrile for $16 \mathrm{~h}$ at $25^{\circ} \mathrm{C}$ gave after hydrolysis with aqueous $\mathrm{NaHCO}_{3}$ and preparative TLC (ether - pentane $3: 1$ ) $162 \mathrm{mg}(41 \%)$ of 4 , identical (NMR) with the product described above, followed by two unidentified, slower-moving products (24 and $122 \mathrm{mg}$ respectively).

1,6-Anhydro-2-O-( N-methyl)benzimidoyl-3,4-O(S)-benzylidene- $\beta$-D-galactopyranose ( $5 \mathrm{~h}$ ). To $1.25 \mathrm{~g}$ of a $50 \%$ sodium hydride suspension in mineral oil in $35 \mathrm{ml}$ of THF was added $0.1 \mathrm{~g}$ imidazole followed by $4.0 \mathrm{~g}$ of benzylidene-galactosan (1) in two portions, and the suspension was stirred for 15 min at $20^{\circ} \mathrm{C}$. $N$-Methyl-benzimidoyl chloride ${ }^{17}$ $(2.60 \mathrm{~g})$ in THF $(15 \mathrm{ml})$ was added and the mixture was stirred for $30 \mathrm{~min}$ at $20^{\circ} \mathrm{C}$ and $1 \mathrm{~h}$ under reflux, diluted with dichloromethane and poured into ice-water - dichlormethane under vigorous stirring. The organic phase was rapidly separated, dried $\left(\mathrm{MgSO}_{4}\right)$ and treated with activated carbon and concentrated to $50 \mathrm{ml}$. Dropwise addition of a dry $0.5 \mathrm{M}$ hydrogen chloride in ether until acidic, followed by dropwise addition of $100 \mathrm{ml}$ of dry ether gave the iminoester hydrochloride in an easily filtered form. The iminoester hydrochloride was suspended in chloroform $(100 \mathrm{ml})$ - water $(100 \mathrm{ml})$ and potassium carbonate added to give $\mathrm{pH} 10$, the organic phase was separated, dried $\left(\mathrm{MgSO}_{4}\right)$, treated with activated carbon, evaporated to dryness and crystallized from ethyl acetate $(20 \mathrm{ml})-$ pentane $(20 \mathrm{ml})$ to give $2.7 \mathrm{~g}(46 \%)$ of $5 \mathrm{~h}$, m.p. $100-102{ }^{\circ} \mathrm{C},[\alpha]_{\mathrm{D}}{ }^{25}+77^{\circ}(c 1.1)$. Anal. $\mathrm{C}_{21} \mathrm{H}_{21} \mathrm{NO}_{5}$ : $\mathrm{C}, \mathrm{H}, \mathrm{N} .{ }^{1} \mathrm{H}$ NMR: $\delta 5.59$ (H1), $5.34(\mathrm{H} 2), 4.5-4.6$ (H3, H4), 4.29 (H5), 4.13 (H6), 3.53 (H6'), 5.81 $(\mathrm{ArCH}), 3.10\left(\mathrm{NCH}_{3}\right) ; J_{12}, J_{23}<1 \mathrm{~Hz}, J_{66}=7.6$. ${ }^{13} \mathrm{C}$ NMR: $\delta 99.1$ (C1), 70.5 (C2), 76.2 (C3), 69.4
(C4), 72.1 (C5), 63.3(C6), 102.6( $\mathrm{ArCH}), 37.0\left(\mathrm{NCH}_{3}\right)$. Concentration of the mother liquors gave further $0.5 \mathrm{~g}$ of $6 h$, m.p. $99-101{ }^{\circ} \mathrm{C}$.

1,6-Anhydro-2,4-di-O-benzoyl-3-deoxy-3-methylamino- $\beta$-D-gulopyranose (11). Treatment of $5 h(502$ $\mathrm{mg})$ with trityl fluoroborate $(790 \mathrm{mg})$ in acetonitrile $(10 \mathrm{ml})$ for $6 \mathrm{~h}$ at $20^{\circ} \mathrm{C}$ and $16 \mathrm{~h}$ at $40^{\circ} \mathrm{C}$ gave the oxazolinium salt $7 h$, which was hydrolyzed by stirring with $10 \mathrm{ml}$ of water for $2 \mathrm{~h}$ at $20^{\circ} \mathrm{C}$. Addition of potassium carbonate $(0.5 \mathrm{~g})$ liberated the amine 11. Extraction with chloroform, drying $\left(\mathrm{MgSO}_{4}\right)$ and evaporation to dryness gave crude 11, sirup, ${ }^{1} \mathrm{H}$ NMR: $\delta 5.64(\mathrm{H} 1), 5.37(\mathrm{H} 2), 3.24$ (H3), 5.30 (H4), 4.69 (H5), 4.22 (H6), 3.77 (H6) $), 2.39$ $\left(\mathrm{NCH}_{3}\right) ; J_{12}=2.3 \mathrm{~Hz}, J_{23}=4.5, J_{34}=10.0, J_{45}=$ $4.0, J_{56} \simeq 0, J_{56}=4.7, J_{66^{\prime}}=7.7 .{ }^{13} \mathrm{C}$ NMR: $\delta 99.3$ (C1), 56.0 (C3), 72.4 (C5), 64.4 (C6), 71.7 and 69.4 (C2, C4), 33.9 ( $\left.\mathrm{NCH}_{3}\right)$. Redissolution in dichloromethane $(10 \mathrm{ml})$ and dropwise addition of $20 \mathrm{ml} 0.1 \mathrm{M}$ hydrogen chloride in ether precipitated $244 \mathrm{mg}$ $(43 \%)$ of 11 as the hydrochloride, m.p. $230-231^{\circ} \mathrm{C}$ (dest). Recrystallization from acetonitrile (100 parts) gave a product containing varying amounts of acetonitrile, but drying for 2 weeks at $20^{\circ} \mathrm{C}$ and $0.01 \mathrm{~mm} \mathrm{Hg}$ gave solvent-free material, m.p. $228-$ $229^{\circ} \mathrm{C}$ (dest). Anal. $\mathrm{C}_{21} \mathrm{H}_{22} \mathrm{NO}_{6} \mathrm{Cl}: \mathrm{C}, \mathrm{H}, \mathrm{N}, \mathrm{Cl}$.

1,6-Anhydro-3-(N-methyl)benzamido-4-O-benzoyl-3-deoxy- $\beta$-D-gulopyranose (12). The oxazolinium ion $7 h$ was prepared from $5 h(629 \mathrm{mg})$ and trityl fluoroborate $(739 \mathrm{mg})$ as described above, and hydrolyzed by stirring with aqueous $\mathrm{NaHCO}_{3}$ for $3 \mathrm{~h}$. Extraction with chloroform gave on drying $\left(\mathrm{MgSO}_{4}\right)$ and evaporation a crude product which crystallized from ether-pentane to give $254 \mathrm{mg}$ $(39 \%)$ of 12 , m.p. $116-118^{\circ} \mathrm{C}$. Recrystallization from ethyl acetate - pentane gave m.p. $119-121^{\circ} \mathrm{C}$, $[\alpha]_{\mathrm{D}}{ }^{25}+48^{\circ}$ (c 1.4), anal. $\mathrm{C}_{21} \mathrm{H}_{21} \mathrm{NO}_{6}: \mathrm{C}, \mathrm{H}, \mathrm{N} .{ }^{1} \mathrm{H}$ NMR: lines too broad for interpretation. ${ }^{13} \mathrm{C}$ NMR showed two superimposed spectra in an intensity ratio of $5: 1$, the major component having the following absorptions: $\delta 102.0$ (C1), 72.3, 71.8 and 66.7 (C2, C4, C5), 64.0 (C6), 52.7 (C3), 36.1 ( $\left.\mathrm{NCH}_{3}\right)$, and the minor component having: $\delta 55.8(\mathrm{C} 3), 30.8$ $\left(\mathrm{NCH}_{3}\right)$. Addition of trifluoroacetic acid $(1 \mathrm{dr})$ to the sample resolved the ${ }^{1} \mathrm{H}$ NMR spectrum in two superimposed spectra also in the intensity ratio of $5: 1$, the major component having the following spectrum: $\delta 5.59(\mathrm{H} 1), 4.49(\mathrm{H} 2), 5.00(\mathrm{H} 3), 6.04$ (H4), 4.93 (H5), 4.43 (H6), $3.92\left(\mathrm{H}^{6}\right), 3.13\left(\mathrm{NCH}_{3}\right)$; $J_{12}=2.2 \mathrm{~Hz}, J_{23}=4.4, J_{34}=11.1, J_{45}=4.5, J_{56} \simeq 0$, $J_{56^{\prime}}=4.9, J_{66^{\prime}}=8.5$, and the minor component having $\delta 5.43(\mathrm{H} 1), 5.88(\mathrm{H} 4), 3.29\left(\mathrm{NCH}_{3}\right) J_{12} \simeq 2$ $\mathrm{Hz}, J_{45} \simeq 4$. After 1 week at $20^{\circ} \mathrm{C}$ complete rearrangement to 11 (as the trifluoroacetate) had taken place, ${ }^{1} \mathrm{H}$ NMR: $\delta 5.28(\mathrm{H} 1), 5.63(\mathrm{H} 2), 5.82(\mathrm{H} 4)$, 4.90 (H5), 4.36 (H6), $3.94\left(\mathrm{H6}^{\prime}\right), 2.88\left(\mathrm{NCH}_{3}\right)$; $J_{12}=2.3 \mathrm{~Hz}, J_{23}=4.3, J_{34}=10.0, J_{45}=4.4, J_{56} \simeq 0$,

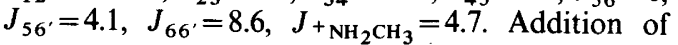


$\mathrm{D}_{2} \mathrm{O}$ changes the methyl signal to a singlet and causes the $\mathrm{H} 3$ signal to appear at $\delta 4.14 .{ }^{13} \mathrm{C}$ NMR: $\delta 98.1$ (C1), 67.1 (C2), 56.3 (C3), 68.1 (C4), 72.3 (C5), 64.6 (C6), $31.7\left(\mathrm{NCH}_{3}\right)$. Addition of $\mathrm{K}_{2} \mathrm{CO}_{3}-\mathrm{D}_{2} \mathrm{O}$ to the NMR samples gave ${ }^{1} \mathrm{H}$ and ${ }^{13} \mathrm{C}$ NMR spectra of 11 (as the free base) identical to those described above. The ${ }^{13} \mathrm{C}$ NMR sample was worked up to the hydrochloride as described above, m.p. $228-230{ }^{\circ} \mathrm{C}$.

1,6-Anhydro-3,4-O-(S)-benzylidene-2-O-methoxycarbonyl- $\beta$-D-galactopyranose (5b). Methoxycarbonyl chloride $(0.5 \mathrm{ml})$ was added to a solution of benzylidene galactosan $(1,1.00 \mathrm{~g})$ in pyridine $(10 \mathrm{ml})$ at $-78^{\circ} \mathrm{C}$ and the solution was allowed to come to $20^{\circ} \mathrm{C}(1.5 \mathrm{~h})$. The solution was cooled to $-78^{\circ} \mathrm{C}$ and a further $0.5 \mathrm{ml}$ methoxycarbonyl chloride was added and the solution left $16 \mathrm{~h}$ at $20{ }^{\circ} \mathrm{C}$. Addition of water precipitated $0.87 \mathrm{~g}(70 \%)$ of 5b, m.p. $98-99^{\circ} \mathrm{C}$. Recrystallization from ether pentane gave m.p. $100-101^{\circ} \mathrm{C},[\alpha]_{\mathrm{D}}{ }^{28}+31^{\circ}(c 1.2)$. Anal. $\mathrm{C}_{15} \mathrm{H}_{16} \mathrm{O}_{7} ; \mathrm{C}, \mathrm{H} .{ }^{1} \mathrm{H}$ NMR: $\delta 5.54(\mathrm{H} 1)$, 4.94 (H2), 4.25 (H3), 4.8 (H4, H5), 4.15 (H6), 3.54 $\left(\mathrm{H}^{\prime}\right), 5.88(\mathrm{ArCH}), 4.08\left(\mathrm{OCH}_{3}\right) ; J_{12}, J_{23}, J_{56}<1$ $\mathrm{Hz}, J_{66^{\prime}}=7.9 .{ }^{13} \mathrm{C}$ NMR: $\delta 98.4$ (C1), 72.0 (C2), 75.4 (C3), 69.0 (C4), 73.7 (C5), 63.4 (C6), 101.4 $(\mathrm{ArCH})$.

1,6-Anhydro-4-O-benzoyl-2,3-O-carbonato- $\beta$-Dgulopyranose (3). Treatment of $5 b(493 \mathrm{mg})$ with trityl fluoroborate $(653 \mathrm{mg})$ in acetonitrile $(10 \mathrm{ml})$ for $16 \mathrm{~h}$ at $20^{\circ} \mathrm{C}$ followed by hydrolysis with aqueous $\mathrm{NaHCO}_{3}$ and extraction with chloroform gave a crude product, which crystallized from ethyl acetate - chloroform to give $345 \mathrm{mg} \mathrm{(74 \% )} \mathrm{of} \mathrm{3,} \mathrm{m.p.}$ $215-217^{\circ} \mathrm{C}$. Recrystallization from chloroform pentane gave m.p. $216-217^{\circ} \mathrm{C},[\alpha]_{\mathrm{D}}{ }^{25}+95^{\circ}(c 1.1$, DMSO). Anal. $\mathrm{C}_{14} \mathrm{H}_{12} \mathrm{O}_{7}: \mathrm{C}, \mathrm{H}$. IR: 1730,1805 $\mathrm{cm}^{-1} .{ }^{1} \mathrm{H}$ NMR (acetonitrile-d $\left.{ }_{3}\right): \delta 5.76(\mathrm{H} 1), 4.76$ (H2), 5.10 (H3), 5.40 (H4), 4.91 (H5), 4.18 (H6), 3.78 $\left(\mathrm{H6}^{\prime}\right) ; J_{12}=1.1 \mathrm{~Hz}, J_{23}=8.0, J_{34}=4.6, J_{45}=6.0$, $J_{56}=1.5, J_{56^{\prime}}=5.5, J_{66^{\prime}}=8.6 .{ }^{13} \mathrm{C}$ NMR (acetonitrile-d $\left.\mathrm{d}_{3}\right)$ : $96.9(\mathrm{C} 1), 74.4(\mathrm{C} 2), 74.9$ (C3), 71.1 (C4), 70.1 (C5), 63.2 (C6), (DMSO-d 6 ) 164.5, $153.4(\mathrm{C}=0)$. Preparative TLC of the mother liquor gave a further $36 \mathrm{mg}(8 \%)$ of 3 .

Deacylation of 3 with sodium methoxide in methanol gave 1,6-anhydro- $\beta$-D-gulopyranose as a syrup (identified by its ${ }^{13} \mathrm{C}$ NMR spectrum ${ }^{18}$ ) which was acetylated to give 2,3,4-tri-O-acetyl-1,6anhydro- $\beta$-D-gulopyranose, m.p. $111-112^{\circ} \mathrm{C}$ (lit. ${ }^{19}$ m.p. $114-115^{\circ} \mathrm{C}$ ).

1,6-Anhydro-3,4-O-(S)-benzylidene-2-O-phenoxycarbonyl- $\beta$-D-galactopyranose ( $5 \mathrm{c})$. Benzylidene galactosan $(1,1.00 \mathrm{~g})$ was acylated with phenoxycarbonyl chloride $(0.64 \mathrm{ml})$ in pyridine $(10 \mathrm{ml})$ for $16 \mathrm{~h}$ at $20^{\circ} \mathrm{C}$. Addition of water precipitated $5 \mathrm{c}$. Recrystallization from acetone - ethanol gave $1.10 \mathrm{~g}$ $(74 \%)$ of $5 c$, m.p. $151-153^{\circ} \mathrm{C}$. Recrystallization from ethyl acetate - pentane gave m.p. $153-154^{\circ} \mathrm{C}$,
$[\alpha]_{\mathrm{D}}{ }^{25}+39^{\circ}$ (c 1.3). Anal. $\mathrm{C}_{20} \mathrm{H}_{18} \mathrm{O}_{7}: \mathrm{C}, \mathrm{H} .{ }^{1} \mathrm{H}$ NMR: $\delta 5.57$ (H1), $5.00(\mathrm{H} 2), 4.3(\mathrm{H} 3), 4.6(\mathrm{H} 4, \mathrm{H} 5)$, 4.10 (H6), $3.52\left(\mathrm{H} 6^{\prime}\right), 5.83(\mathrm{ArCH}) ; J_{12}, J_{23}, J_{56}$ $<1 \mathrm{~Hz}, J_{56^{\prime}}=4.9, J_{66^{\prime}}=7.9$.

Acknowledgements. Microanalyses were performed by Novo Microanalytical Laboratory. The pulsed Fourier spectrometers were provided by the Danish Natural Science Research Council.

\section{REFERENCES}

1. Jacobsen, S., Nielsen, B. and Pedersen, C. Acta Chem. Scand. B 31 (1977) 359.

2. Jacobsen, S. and Pedersen, C. Acta Chem. Scand. B 31 (1977) 365.

3. Hünig, S. Angew. Chem. 76 (1964) 400.

4. Meerwein, H., Bodenbenner, K., Borner, P., Kunert, F. and Wunderlich, K. Justus Liebigs Ann. Chem. 632 (1960) 38.

5. Jacobsen, S. and Mols, O. Acta Chem. Scand. B 35 (1981) 169.

6. Hoffmeyer, L., Jacobsen, S., Mols, O. and Pedersen, C. Acta Chem. Scand. B 33 (1979) 175.

7. Kalinowski, H.-O. and Kessler, H. Angew. Chem. 86 (1974) 43.

8. Lee, L. A. and Wheeler, J. W. J. Org. Chem. 37 (1972) 497.

9. Olah, G. A. and Kiovsky, T. E. J. Am. Chem. Soc. 90 (1968) 4666.

10. Kabuss, S. Angew. Chem. 78 (1966) 714.

11. Dimroth, K. and Heinrich, P. Angew. Chem. 78 (1966) 714.

12. Ramsey, B. G. and Taft, R. W. J. Am. Chem. Soc. 88 (1966) 3058.

13. Tomalia, D. A. and Hart, H. Tetrahedron Lett. (1967) 3383, 3389.

14. Martin, R. H., Lampe, F. W. and Taft, R. W. J. Am. Chem. Soc. 88 (1966) 1353.

15. Taft, R. W., Martin, R. H. and Lampe, F. W. J. Am. Chem. Soc. 87 (1965) 2490.

16. Barton, D. H. R. and McCombie, S. W. J. Chem. Soc. Perkin Trans. 1 (1975) 1574.

17. v. Braun, J. and Pinkernelle, W. Ber. Dtsch. Chem. Ges. 67 (1934) 1218.

18. Paulsen, H., Sinnwell, V. and Greve, W. Carbohydr. Res. 49 (1976) 27.

19. Stewart, L. C. and Richtmyer, N. K. J. Am. Chem. Soc. 77 (1955) 1021.

Received May 27, 1981. 